\title{
Study on the Inhibition of Mild Steel Corrosion by Benzoisoxazole and Benzopyrazole Derivatives in $\mathrm{H}_{2} \mathrm{SO}_{4}$ Medium
}

\author{
K. Parameswari, 'S. Rekha, S. Chitra, E. Kayalvizhy \\ P.S.G.R. Krishnammal College for Women, Coimbatore, Tamilnadu, India.
}

\begin{abstract}
Four heterocyclic compounds, namely 4- phenyl-5-acetyl/carbethoxy-3-methyl-6hydroxyl-6-methyl-4,5,6,7-tetrahydro-2,1-benzoisoxazole and benzopyrazole (BIS1, BP1and BIS2, BP2), were synthesized and their influence on the inhibition of corrosion of mild steel in $1 \mathrm{M} \mathrm{H}_{2} \mathrm{SO}_{4}$ was investigated by means of weight loss, potentiodynamic polarization, electrochemical impedance (EIS) and scanning electron microscopy (SEM). The values of activation energy and free energy of adsorption of these compounds were also calculated. Adsorption obeys Langmuir adsorption isotherm. The IE of the compounds was found to vary with concentration and temperature. Synergistic effect was also investigated for the four compounds at $0.05 \mathrm{mM}$ concentration by weight loss method in $1 \mathrm{M} \mathrm{H}_{2} \mathrm{SO}_{4}$ medium in presence of $\mathrm{KI}, \mathrm{KBr}$ and $\mathrm{KCl}$. Results obtained revealed that all the four compounds performed excellently as a corrosion inhibitor for mild steel in $1 \mathrm{M} \mathrm{H}_{2} \mathrm{SO}_{4}$ and their efficiency attains more than $90 \%$ at 0.6 $\mathrm{mM}$ at $298 \mathrm{~K}$. Polarisation studies showed them to be mixed type inhibitors.
\end{abstract}

Keywords: corrosion inhibition, weight loss, potentiodynamic polarization, EIS, synergism SEM.

\section{Introduction}

It is well documented that, the development of new corrosion inhibitors of nontoxic type, which do not contain heavy metals and organic phosphates, is very important [1]. Inorganic compounds such as chromate, dichromate, nitrite and nitrate are widely used as corrosion inhibitors in several media and for different metals and alloys [2,3]. On the other hand, the biotoxicity of these products,

\footnotetext{
* Corresponding author. E-mail address: parampps@yahoo.co.in
} 
especially chromate, is well documented [4] as well as their non-environmentalfriendly characteristics [5] which limit their application. Among alternative corrosion inhibitors, organic compounds containing $\mathrm{N}, \mathrm{S}$ and $\mathrm{O}$ have been reported as inhibitors which reduce the rate of the dissolution of metals $[6,7]$.

These organic compounds adsorb on metallic surface and decrease the corrosion rate. The most efficient inhibitors are compounds containing л bonds in their structures. The adsorption of these compounds is influenced by the electronic structure of inhibiting molecules, steric factor, aromaticity and electron density at the donor site, presence of functional group such as $-\mathrm{CHO},-\mathrm{N}=\mathrm{N}, \mathrm{R}-\mathrm{OH}$, etc., molecular area and molecular weight of the inhibitor molecule [8].

$\mathrm{N}$-heterocyclic compounds act by adsorption on the metal surface, and the adsorption takes place through nitrogen atom, as well as with triple or conjugated double bonds or aromatic rings in their molecular structures. Up to now, many N-heterocyclic compounds, such as imidazoline, triazole, pyrimidine, pyrrole' pyridine, etc., derivatives [9-12], have been used for the corrosion inhibition of iron or steel in acidic media. Even though isoxazolidines are easily accessible and known for many decades, only recently, the heterocyclic compounds containing NO moiety embedded in the five-membered ring were introduced to the corrosion literature for the first time [13]. Though the existing data show that numerous $\mathrm{N}$-heterocyclic organic compounds have good anticorrosive activity, some of them are highly toxic to both human beings and environment. The safety and environmental issues of corrosion inhibitors arisen in industries has always been a global concern. These toxic effects have led to the use of eco-friendly and harmless N-heterocyclic compounds as inhibitors.

This work is aimed to study the effect of new synthesized benzopypyrazole and benzoisoxazole for inhibition of the corrosion of mild steel in $1 \mathrm{M} \mathrm{H}_{2} \mathrm{SO}_{4}$ by using techniques such as weight loss, potentiodynamic polarization, electrochemical impedance (EIS) and scanning electron microscopy (SEM). Synergistic effect was also carried out for mild steel samples in $\mathrm{H}_{2} \mathrm{SO}_{4}$ media with $0.05 \mathrm{mM}$ concentration of the inhibitors and halides.

\section{Experimental details}

Preparation of inhibitor

Benzoisoxazole and benzopyrazole derivatives were synthesized by the procedure described by Rajanarendra et al. [14] and were characterized by IR spectra.

\section{Solutions}

$1 \mathrm{M} \mathrm{H}_{2} \mathrm{SO}_{4}$ was prepared by dilution of analytical grade $\mathrm{H}_{2} \mathrm{SO}_{4}$ with distilled water and standardised with a standard base. The concentration range of the inhibitor used was $0.05 \mathrm{mM}-0.6 \mathrm{mM}$ in the acid solution, and $1 \mathrm{M}$ sulphuric acid was used as blank for comparison of results. 
Table 1. Structure of the compounds.

\begin{tabular}{|l|l|c|}
\hline S.No & IUPAC Name \\
\hline 1. & $\begin{array}{l}\text { 4-phenyl-5-acetyl-3-methyl-6-hydroxyl-6-methyl-4,5,6,7- } \\
\text { tetrahydro- 2,1-benzoisoxazole (BIS1) }\end{array}$ \\
\hline 3. & $\begin{array}{l}\text { 4-phenyl-5-acetyl-3-methyl-6-hydroxyl-6-methyl-4,5,6,7- } \\
\text { tetrahydro- 2,1-benzopyrazole (BP1) }\end{array}$ \\
\hline 4. & 4-phenyl-5-carbethoxy-3-ethoxy-6-hydroxyl-6-methyl-4,5,6,7- \\
tetrahydro-2,1- benzoisoxazole (BIS2)
\end{tabular}

\section{Corrosion monitoring techniques}

\section{Weight loss method}

\section{Specimen}

Weight loss experiments were performed with a cold rolled mild steel specimen of area $0.8113 \mathrm{inch}^{2}$ having composition (Wt \%) C-0.07\%, S-Nil, P-0.008\%, SiNil, Mn- $0.34 \%$ and balance Fe; the specimen was polished using series of emery papers and finally degreased with organic solvent trichloroethylene and immediately used for experiments

\section{Experimental procedure}

Weight loss measurements were carried out by weighing the specimens before and after immersion in $100 \mathrm{~mL}$ acid solution for 3 hours in the absence and presence of inhibitors at various concentrations. Duplicate experiments (triplicate) were performed in each case and mean value of the weight loss was determined. From the initial and final masses of the specimen the weight loss was calculated. From this weight loss value, inhibition efficiency and corrosion rate were determined. Inhibition efficiency has been determined by the following relationship,

$$
\text { Inhibition efficiency }(\%)=[(\mathrm{Wb}-\mathrm{Wi}) / \mathrm{Wb}] \times 100
$$

where $\mathrm{Wb}$ and $\mathrm{Wi}$ are the weight loss without and with inhibitor, respectively. 
The corrosion rate has been determined by the relationship,

$$
\text { Corrosion rate }(\mathrm{mpy})=(534 \times \mathrm{W}) /(\mathrm{A} \times \mathrm{T} \times \mathrm{D})
$$

where $\mathrm{W}=$ weight loss in $\mathrm{mg} ; \mathrm{A}=$ area in inch $^{2}$; $\mathrm{T}=$ time of immersion in sec; and $\mathrm{D}=$ density in $\mathrm{g} / \mathrm{cm}^{3}$.

The surface coverage $(\theta)$ has been determined using the following relationship:

$$
\text { Surface coverage }(\theta)=(\mathrm{Wb}-\mathrm{Wi}) / \mathrm{Wb}
$$

\section{Temperature studies}

The same procedure was carried out at different temperatures $(303,313,323$ and $333 \mathrm{~K}$ ) using a thermostat to study the inhibition efficiency of the inhibitors at higher temperatures. This study gives details about the nature of adsorption and activation energy.

\section{Synergistic effects of halide ions}

The synergistic effect was studied in the presence of $1 \mathrm{mM} \mathrm{KCl}, \mathrm{KBr}$ and $\mathrm{KI}$ to the steel specimen immersed for 3 hours in $1 \mathrm{M}$ sulphuric acid containing 0.05 $\mathrm{mM}$ concentration of the inhibitors. The same weight loss method procedure has been followed to study the synergistic effect. From the weight loss data, the corrosion rate and the inhibition efficiency were calculated.

\section{Electrochemical studies}

\section{Electrode surface preparation}

The mild steel rod embedded in teflon with an exposed area of 0.8113 inch $^{2}$ was polished using 1/0, 2/0,3/0 and 4/0 grade emery papers and finally degreased with trichloroethylene and immediately used for the experiments.

Electrode cell assembly

Electrochemical measurements were carried out with a three electrode cell assembly. The working electrode was the mild steel rod. A saturated calomel electrode was used as the reference electrode. A rectangular Pt foil was used as the counter electrode. The solution capacity is $100 \mathrm{~mL}$.

\section{$\underline{\text { Procedure }}$}

Electrochemical impedance spectroscopy (EIS) and Tafel polarization were conducted in an electrochemical measurement unit (Model 1280 B Solartron, UK). The EIS measurements were made at a corrosion potential over a frequency range of $10 \mathrm{kHz}$ to $0.01 \mathrm{~Hz}$ with signal amplitude of $10 \mathrm{mV}$. The Tafel polarization measurements were made after EIS for a potential range of -200 mV to $+200 \mathrm{mV}$ with respect to open circuit potential, at a scan rate of $1 \mathrm{mV} / \mathrm{sec}$. The $\mathrm{I}_{\text {corr }}, \mathrm{E}_{\mathrm{corr}}, \mathrm{R}_{\mathrm{ct}}$ and $\mathrm{C}_{\mathrm{dl}}$ values were obtained from the data using the corresponding "Corr view" and "Zview" software. The inhibition efficiency from potentiodynamic polarization was calculated from the value of $\mathrm{I}_{\text {corr }}$ by using the formula

$$
\text { Inhibition efficiency }(\%)=\left[\left(\mathrm{I}_{\text {corr (blank) }}-\mathrm{I}_{\text {corr (inh) }}\right) / \mathrm{I}_{\text {corr (blank) }}\right] \times 100
$$


The inhibition efficiency from the impedance measurements was calculated using the formula

$$
\text { Inhibition efficiency }(\%)=\left[\left(\mathrm{R}_{\mathrm{ct}(\mathrm{inh})}-\mathrm{R}_{\mathrm{ct}(\text { blank })}\right) / \mathrm{R}_{\mathrm{ct}(\mathrm{inh})}\right] \times 100
$$

where $R_{c t(i n h)}$ is the charge transfer resistance in the presence of inhibitor and $\mathrm{R}_{\mathrm{ct}(\text { blank) }}$ is the charge transfer resistance in the absence of inhibitor.

\section{SEM studies}

The surface morphology of the corroded and inhibited mild steel specimen was studied by SEM. The SEM photographs were recorded using a Geol scanning electron microscope. The mild steel specimen was suspended for 3 hrs in blank $\mathrm{H}_{2} \mathrm{SO}_{4}$ and $\mathrm{H}_{2} \mathrm{SO}_{4}$ containing $0.6 \mathrm{mM}$ of compound BIS1. The plates were washed with running water and dried used for SEM studies.

\section{Results and discussion}

\section{Weight loss studies}

The effect of addition of the benzopyrazoles and benzoisoxazoles tested at different concentrations on the corrosion of mild steel in $1 \mathrm{M} \mathrm{H}_{2} \mathrm{SO}_{4}$ was studied by weight loss method at $303 \mathrm{~K}$ after $3 \mathrm{hrs}$ of immersion period. The values of corrosion rate and inhibition efficiency are given in the Table 2. For each compounds tested the I.E. increases with increasing concentration of the inhibitors (Fig. 1). The increase in efficiency with increasing the concentration is due to increase in surface coverage $\theta$, which shows that the compounds form a protective adsorptive layer on the surface. Thus adsorption forms the mechanism of inhibition.

\section{Effect of temperature}

To investigate the mechanism of inhibition and to determine the activation energies of the corrosion process, the weight loss studies were carried out at higher temperatures from 313-333 K. The results are given in Table 3. The inhibition efficiency decreases with temperature for all the inhibitors.

Fig. 1 presents the Arrhenius plots of log corrosion rate vs. 1/T for $1 \mathrm{M} \mathrm{H}_{2} \mathrm{SO}_{4}$ with and without the addition of the inhibitors and the slopes of the straight lines permit the calculation of Arrhenius activation energy, $\mathrm{E}_{\mathrm{a}}$.

The values of $E_{a}$ increase in the presence of inhibitors, which is shown in Table 4. Szauer, Brandt [15] and Foroulis [16] proposed that the lower activation energy value of the process in the presence of the inhibitor compared to that in its absence is attributed to chemisorptions, while the opposite is attributed to physical adsorption. The increase in Ea in the presence of benzopyrazoles and benzoisoxazoles indicates physical or weak bonding between the molecules of the inhibitor and the mild steel surface. The standard free energy of adsorption $\Delta \mathrm{G}^{\circ}$ ads can be calculated using the relation

$$
\mathrm{K}_{\mathrm{ads}}=1 / 55.5 \exp \left(-\Delta \mathrm{G}^{\circ}{ }_{\mathrm{ads}} / \mathrm{RT}\right)
$$


where 55.5 is the concentration of water in solution in moles / lit. The negative values of $\Delta \mathrm{G}^{\circ}$ ads (Table 4) ensure the spontaneity of the adsorption process and the stability of the adsorbed layer. Generally, values of $\Delta \mathrm{G}^{\circ}$ ads up to $-20 \mathrm{KJ} \mathrm{mol}^{-1}$ are consistent with physical adsorption, i.e., electrostatic interactions between the charged molecules and charged metal surface, while those around $-40 \mathrm{~kJ} \mathrm{~mol}^{-1}$ or higher are associated with chemisorptions as a result of sharing or transfer of electrons from organic molecules to metal surface [17].

Table 2. Inhibition efficiency of various concentrations of the inhibitors for the corrosion of mild steel in $1 \mathrm{M} \mathrm{H}_{2} \mathrm{SO}_{4}$ by weight loss method at $30 \pm 1{ }^{\circ} \mathrm{C}$.

\begin{tabular}{|c|c|c|c|c|c|}
\hline S.no & $\begin{array}{c}\text { Inhibitor } \\
\text { concentration } \\
(\mathbf{m M})\end{array}$ & $\begin{array}{l}\text { Weight } \\
\text { loss } \\
\text { (g) }\end{array}$ & $\begin{array}{l}\text { Corrosion } \\
\text { rate } \\
\text { (mpy) }\end{array}$ & $\begin{array}{l}\text { Inhibitor } \\
\text { efficiency } \\
(\%)\end{array}$ & $\begin{array}{c}\text { Surface } \\
\text { coverage } \\
\theta\end{array}$ \\
\hline \multicolumn{6}{|c|}{ BI S1 } \\
\hline 1. & Blank & 0.2651 & 7699.83 & & \\
\hline 2. & 0.05 & 0.1051 & 3052.63 & 60.36 & 0.6036 \\
\hline 3. & 0.1 & 0.0427 & 1240.22 & 83.89 & 0.8389 \\
\hline 4. & 0.3 & 0.0135 & 392.11 & 94.91 & 0.9491 \\
\hline 5. & 0.6 & 0.0045 & 130.70 & 98.3 & 0.983 \\
\hline \multicolumn{6}{|c|}{ BP1 } \\
\hline 1. & Blank & 0.2606 & 7569.13 & & \\
\hline 2. & 0.05 & 0.13 & 3775.85 & 50.11 & 0.5011 \\
\hline 3. & 0.1 & 0.1001 & 2907.40 & 61.59 & 0.6159 \\
\hline 4. & 0.3 & 0.02 & 580.90 & 92.33 & 0.9233 \\
\hline 5. & 0.6 & 0.013 & 377.59 & 95.01 & 0.9501 \\
\hline \multicolumn{6}{|c|}{ BIS2 } \\
\hline 1. & Blank & 0.2322 & 6744.25 & & \\
\hline 2. & 0.05 & 0.1151 & 3343.08 & 50.43 & 0.5043 \\
\hline 3. & 0.1 & 0.088 & 2555.96 & 62.1 & 0.621 \\
\hline 4. & 0.3 & 0.0357 & 1036.91 & 84.63 & 0.8463 \\
\hline 5. & 0.6 & 0.0206 & 598.33 & 91.13 & 0.9113 \\
\hline \multicolumn{6}{|c|}{ BP2 } \\
\hline 1. & Blank & 0.277 & 8045.47 & & \\
\hline 2. & 0.05 & 0.1203 & 3494.11 & 56.57 & 0.5657 \\
\hline 3. & 0.1 & 0.092 & 2672.14 & 66.79 & 0.6679 \\
\hline 4. & 0.3 & 0.0333 & 967.20 & 87.98 & 0.8798 \\
\hline 5. & 0.6 & 0.0233 & 676.75 & 91.59 & 0.9159 \\
\hline
\end{tabular}

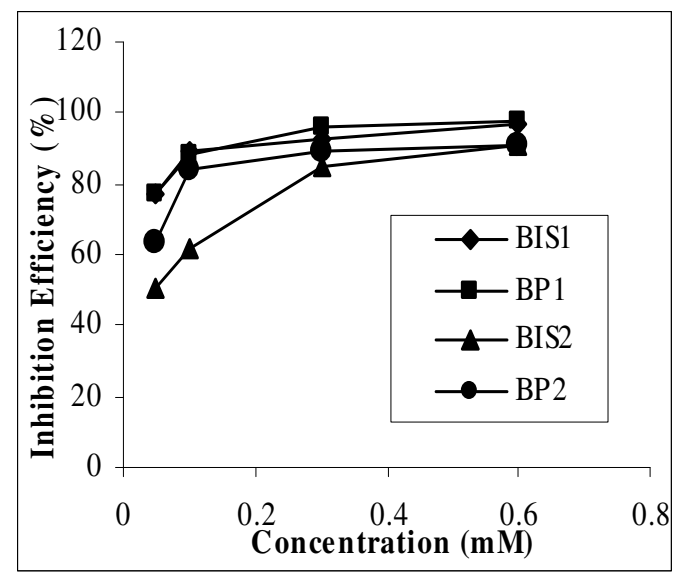

Figure 1. Variation of inhibition efficiency (\%) vs. concentration of the inhibitors $(\mathrm{mM})$. 
Table 3. Inhibition efficiency at $0.6 \mathrm{mM}$ concentration of the inhibitors for the corrosion of mild steel in $1 \mathrm{M} \mathrm{H}_{2} \mathrm{SO}_{4}$ by weight loss method at higher temperatures.

\begin{tabular}{|c|c|c|c|c|}
\hline \multirow{2}{*}{ Inhibitor } & \multicolumn{4}{|c|}{ Inhibition efficiency \% } \\
\cline { 2 - 5 } & $\mathbf{3 0 3} \mathbf{~ K}$ & $\mathbf{3 1 3} \mathbf{~ K}$ & $\mathbf{3 2 3} \mathbf{~ K}$ & $\mathbf{3 3 3} \mathbf{~ K}$ \\
\hline BIS1 & 98.30 & 95.01 & 91.13 & 91.59 \\
\hline BP1 & 93.43 & 87.93 & 80.54 & 68.41 \\
\hline BIS2 & 93.06 & 85.31 & 77.04 & 64.80 \\
\hline BP2 & 84.58 & 82.35 & 74.07 & 62.44 \\
\hline
\end{tabular}

\section{Adsorption isotherm}

Adsorption isotherms are very important in determining the mechanism of organic electrochemical reactions. The most frequently used isotherms are Langmuir, Temkin and Frumkin. The compounds follow Langmuir adsorption isotherm, which is given as

Rearranging this equation

$$
\theta /(1-\theta)=\mathrm{KC}
$$

$$
\mathrm{C} / \theta=1 / \mathrm{K}+\mathrm{C}
$$

where $\theta$ is the surface coverage degree, $K$ the equilibrium constant of the adsorption process and $\mathrm{C}$ is the inhibitor concentration. It was found that a plot of $\mathrm{C} / \theta$ vs. $\mathrm{C}$ is a straight line for all the inhibitors. Fig. 2 depicts the graph of the Langmuir adsorption isotherm for the studied compounds.

As adsorption is of Langmuir character, the organic molecules are attached as a monolayer and through a physical mechanism.

Table 4. Activation energy Ea and free energy of adsorption $\left(\Delta \mathrm{G}^{\circ}\right.$ ads $)$ for the corrosion of mild steel in $1 \mathrm{M} \mathrm{H}_{2} \mathrm{SO}_{4}$ at $0.6 \mathrm{mM}$ concentration of the inhibitors.

\begin{tabular}{|l|c|c|c|c|c|}
\hline \multirow{2}{*}{ Inhibitor } & \multirow{2}{*}{$\mathbf{E}_{\mathbf{a}}(\mathbf{K J})$} & \multicolumn{4}{|c|}{$\Delta \mathbf{G}_{\text {ads }}^{\circ}$} \\
\cline { 3 - 6 } & $\mathbf{3 0 3} \mathbf{~ K}$ & $\mathbf{3 1 3} \mathbf{~ K}$ & $\mathbf{3 2 3} \mathbf{~ K}$ & $\mathbf{3 3 3} \mathbf{~}$ \\
\hline Blank & -32.75 & - & - & - & - \\
\hline BIS1 & -78.15 & -21.19 & -20.03 & -18.83 & -18.28 \\
\hline BP1 & -73.9 & -18.09 & -16.94 & -15.97 & -14.67 \\
\hline BIS2 & -77.53 & -18.00 & -22.33 & -18.04 & -17.80 \\
\hline BP2 & -72.97 & -17.94 & -16.35 & -15.40 & -14.22 \\
\hline
\end{tabular}

\section{Polarization studies}

The inhibition process of the benzopyrazoles and benzoisoxazoles for the corrosion of mild steel in $1 \mathrm{M} \mathrm{H}_{2} \mathrm{SO}_{4}$ was analyzed by polarization experiments. Fig. 3 shows the Tafel anodic and cathodic polarization plots for the inhibitor BIS1. Table 5 gives the values of electrochemical corrosion parameters. It is evident that addition of inhibitors decreased the corrosion current density. The $E_{\text {corr }}$ value is shifted in the noble direction. Further, the Tafel slopes $b_{a}$ and $b_{c}$ are both decreased. But the anodic Tafel slopes are more decreased, showing that the inhibitors, being predominantly anodic, behave as mixed type. 


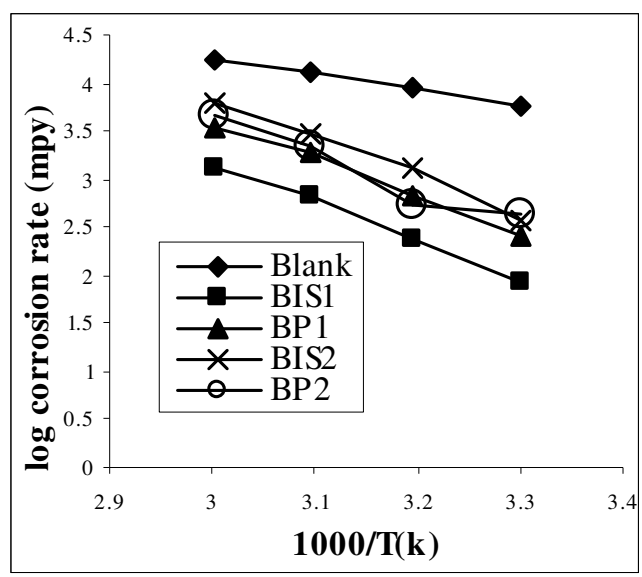

Figure 2. Arrhenius plot of corrosion rate of mild steel in $1 \mathrm{M} \mathrm{H}_{2} \mathrm{SO}_{4}$ solution in the absence and presence of $0.6 \mathrm{mM}$ concentration of the inhibitors.

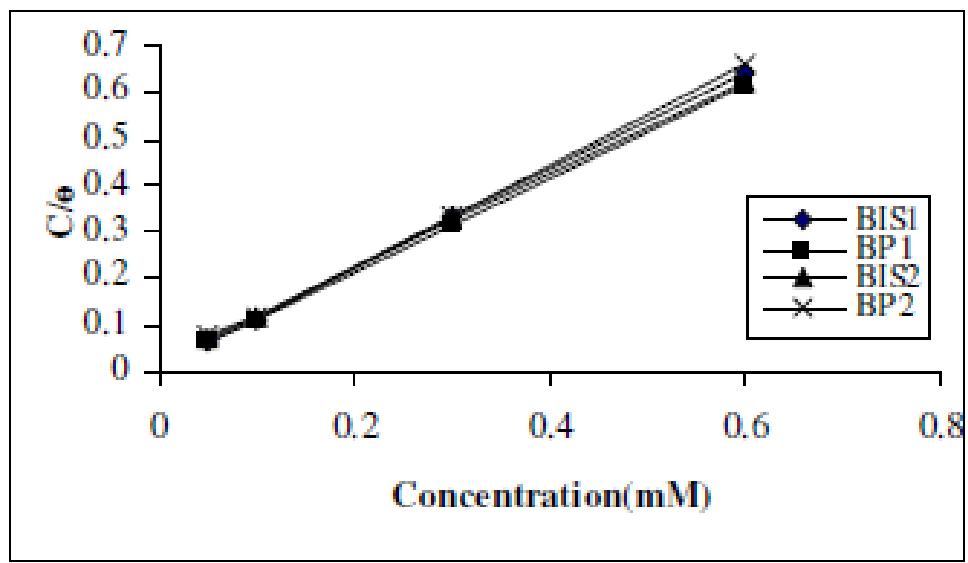

Figure 3. Langmuir plot of the inhibitors.

Table 5. Corrosion parameters for mild steel for various concentrations of the inhibitors in $1 \mathrm{M} \mathrm{H}_{2} \mathrm{SO}_{4}$ by potentiodynamic polarization studies.

\begin{tabular}{|c|c|c|c|c|c|c|}
\hline $\begin{array}{c}\text { Name of } \\
\text { the } \\
\text { inhibitor }\end{array}$ & $\begin{array}{c}\text { Inhibitor } \\
\text { concentration } \\
(\mathbf{m M})\end{array}$ & $\begin{array}{c}\mathbf{I}_{\text {corr }} \\
\boldsymbol{\mu A} / \mathbf{c m} 2\end{array}$ & $\begin{array}{c}\mathbf{E}_{\text {corr }} \\
(\mathbf{m V})\end{array}$ & $\begin{array}{c}\text { ba } \\
(\mathbf{m V / d e c})\end{array}$ & $\begin{array}{c}\text { bc } \\
(\mathbf{m V / d e c})\end{array}$ & $\begin{array}{c}\text { Inhibition } \\
\text { efficiency } \\
(\mathbf{\%})\end{array}$ \\
\hline & Blank & 770 & -592.01 & 184.67 & 206 & \\
\hline \multirow{3}{*}{ BIS1 } & 0.05 & 583 & -580.63 & 164.88 & 200.38 & 23.51 \\
\cline { 2 - 7 } & 0.1 & 329 & -570.37 & 120.75 & 177.71 & 57.28 \\
\cline { 2 - 7 } & 0.3 & 127.36 & -551.58 & 89.033 & 156.38 & 83.46 \\
\cline { 2 - 7 } & 0.6 & 27.694 & -539.38 & 63.701 & 97.842 & 96.40 \\
\hline \multirow{3}{*}{ BP1 } & 0.05 & 420.01 & -574.67 & 140.24 & 183.94 & 45.45 \\
\cline { 2 - 7 } & 0.1 & 232.89 & -567.32 & 108.07 & 172.56 & 69.75 \\
\cline { 2 - 7 } & 0.3 & 163.17 & -559.05 & 98.317 & 159.42 & 78.81 \\
\cline { 2 - 7 } & 0.6 & 94.69 & -548.12 & 83.758 & 158.58 & 87.70 \\
\hline \multirow{3}{*}{ BIS2 } & 0.05 & 508.03 & -579.95 & 151.87 & 201.08 & 34.02 \\
\cline { 2 - 7 } & 0.1 & 311.4 & -575.05 & 122.29 & 175.1 & 59.56 \\
\hline
\end{tabular}

\section{EIS studies}

The anticorrosive performance of the inhibitors was also studied by electrochemical impedance spectra at $30 \pm 1^{\circ} \mathrm{C}$ for various concentrations of the inhibitors in $1 \mathrm{M} \mathrm{H}_{2} \mathrm{SO}_{4}$. The data obtained are given in Table 6. The $\mathrm{R}_{\mathrm{ct}}$ is 
increased in the presence of the inhibitors. Maximum increase was observed for BIS 1 at $0.6 \mathrm{mM}$ concentration.

Table 6. AC impedance parameters for mild steel for various concentrations of the inhibitors in $1 \mathrm{M} \mathrm{H}_{2} \mathrm{SO}_{4}$.

\begin{tabular}{|c|c|c|c|c|}
\hline $\begin{array}{c}\text { Name of } \\
\text { the } \\
\text { inhibitor }\end{array}$ & $\begin{array}{c}\text { Inhibitor } \\
\text { concentration } \\
(\mathbf{m M})\end{array}$ & $\underset{(\text { ohm.cm }}{\text { Ret }}$ & $\begin{array}{c}\text { Cdl } \\
(\mathrm{mV} \text { vs. } \\
\text { SCE)x10 }\end{array}$ & $\begin{array}{c}\text { Inhibition } \\
\text { efficiency } \\
(\%)\end{array}$ \\
\hline & Blank & 3.97 & 12.5 & \\
\hline \multirow{4}{*}{ BIS1 } & 0.05 & 4.7214 & 7.17 & 15.91 \\
\hline & 0.1 & 7.6268 & 7.53 & 47.95 \\
\hline & 0.3 & 15.366 & 7.51 & 74.16 \\
\hline & 0.6 & 23.468 & 8.54 & 83.08 \\
\hline \multirow{4}{*}{ BP1 } & 0.05 & 5.9458 & 7.23 & 33.23 \\
\hline & 0.1 & 11.26 & 8 & 64.74 \\
\hline & 0.3 & 12.132 & 7.5 & 67.28 \\
\hline & 0.6 & 16.89 & 7.91 & 76.49 \\
\hline \multirow{4}{*}{ BIS2 } & 0.05 & 5.666 & 6.88 & 29.93 \\
\hline & 0.1 & 7.39 & 7.26 & 46.28 \\
\hline & 0.3 & 15.854 & 7.8 & 74.96 \\
\hline & 0.6 & 20.559 & 8.72 & 80.69 \\
\hline \multirow{4}{*}{ BP2 } & 0.05 & 7.194 & 6.78 & 44.82 \\
\hline & 0.1 & 8.7462 & 6.55 & 54.61 \\
\hline & 0.3 & 14.584 & 7.02 & 72.78 \\
\hline & 0.6 & 21.058 & 7.27 & 81.15 \\
\hline
\end{tabular}

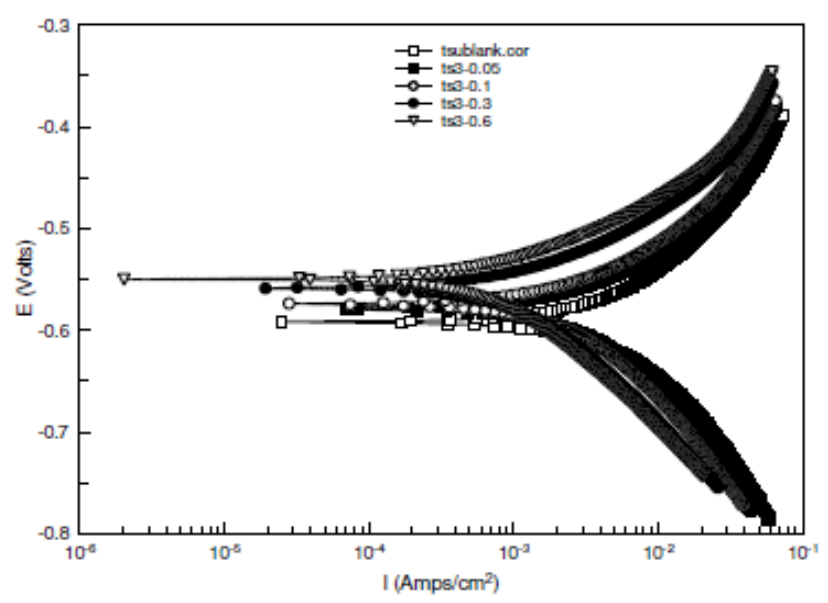

Figure 4. Potentiodynamic polarization curves for mild steel in $1 \mathrm{M} \mathrm{H}_{2} \mathrm{SO}_{4}$ in the absence and presence of selected concentrations of BIS1.

The double layer capacitance $\mathrm{C}_{\mathrm{dl}}$ decreased, as concentration is increased. This decrease may be due to the adsorption of the compounds on the metal surface leading to a film formation. The corresponding Nyquist diagram for BIS1 is shown in Fig. 5. As can be noticed, the impedance diagrams are perfect semicircles, indicating a charge transfer process mainly controlling the corrosion of the steel. 


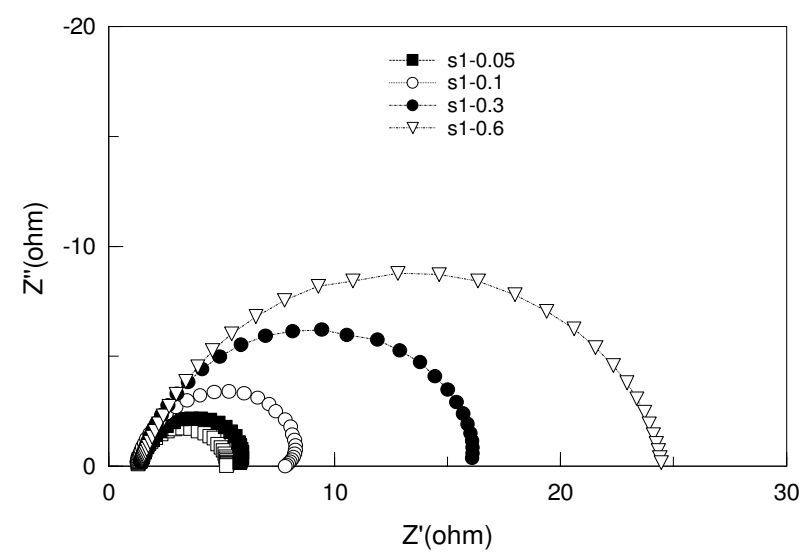

Figure 5. Nyquist plots for mild steel in $1 \mathrm{M} \mathrm{H}_{2} \mathrm{SO}_{4}$ in the absence and presence of selected concentrations of BIS1.

\section{Synergistic effect of halide ion}

Synergism between the organic inhibitor and halide ions on metal corrosion in acidic solution has been researched by many authors [18]. Many studies indicate that nitrogen containing organic compounds have been found to behave better for the steel corrosion in hydrochloric acid than in sulphuric acid. The possible reason is that there is a synergistic inhibition between chloride ion and the nitrogen containing organic compounds [19]. In the present study, an attempt has been made to study the influence of halide ions on the corrosion inhibition of benzopyrazoles and benzoisoxazoles for mild steel in $1 \mathrm{M} \mathrm{H}_{2} \mathrm{SO}_{4}$, by weight loss measurements. The I.E. values obtained are given in Table 7. It is clear from the table that addition of halide ions enhanced the I.E. of all the four inhibitors.

Table 7. Synergistic effect of $1 \mathrm{mM} \mathrm{KCl} / 1 \mathrm{mM} \mathrm{KBr} / 1 \mathrm{mM} \mathrm{KI}$ on the inhibition efficiency of the inhibitors at $0.05 \mathrm{mM}$ concentration by weight loss method.

\begin{tabular}{|c|c|c|c|c|}
\hline \multirow{2}{*}{ Inhibitor } & \multicolumn{4}{|c|}{ Inhibition efficiency \% } \\
\cline { 2 - 5 } & Without halides & With 1 mM KCl & With 1 mM KBr & With 1 mM KI \\
\hline BIS1 & 60.36 & 75.6 & 82.85 & 86.59 \\
\hline BP1 & 50.11 & 69.19 & 72.10 & 77.20 \\
\hline BIS2 & 50.43 & 67.36 & 79.50 & 82.30 \\
\hline BP2 & 56.57 & 73.21 & 80.34 & 84.01 \\
\hline
\end{tabular}

\section{Explanation for synergism}

All the four compounds are nitrogen containing compounds, which contain unshared electron pair and $\pi$-electrons. In strongly acidic solution, they may be protonated leading to a positively charged molecule. It is well known that steel surface contains positive charge due to $\mathrm{E}_{\mathrm{corr}}-\mathrm{E}_{\mathrm{q}=0}>0$ [where $\mathrm{E}_{\mathrm{q}=0}=$ potential of zero charge] [20]. Thus, it is difficult for the positively charged inhibitor molecules to approach the positively charged steel surface due to electrostatic repulsion. Addition of halide ions causes their specific adsorption on the steel and causes the steel surface negatively charged. The protonated organic 
inhibitors are then adsorbed by coulombic attraction on the metal surface and therefore their inhibition efficiency is increased. The synergistic effect increases in the order $\mathrm{Cl}^{-}<\mathrm{Br}^{-}<\mathrm{I}^{-}$. This is because iodide ion is the most adsorbable of halide ions on steel.

\section{Evaluation of the inhibitors}

Analysis of the inhibition efficiency of the compounds tested by all the methods shows the following order of efficiency: BIS1 > BIS2 and BP1 > BP2.

The two sets of compounds have identical general structure, except for the substituents at position 3 and 5 (Table 1). The higher I.E. of BIS1compared to BIS2, and BP1 compared to BP2, may be attributed to the presence of electron donating methyl group in BIS1 and BP1, which enhances the electron density on the isoxazole ring and pyrazole ring, respectively, which are the active sites of adsorption.

BIS2 and BP2 show somewhat lesser I.E. (by about 4-7\%). This may be attributed to the steric interaction of the two bulky -OEt groups at position 3 and 5 with the phenyl ring at position 4 . This steric repulsion makes the -OEt and COOEt groups to be out of the mild steel surface. Therefore, they have no influence on the electron density of the adsorption site (heterocyclic rings).

Comparison of I.E. of isoxazoles and pyrazoles (BIS1 and BP1, BIS2 and BP2) shows that the isoxazoles present slightly higher I.E. than the pyrazoles. Similar results were also reported by Swearingen and Schram [21] for the corrosion of mild steel in the presence of substituted amines. n-propylamine, ethylenediamine and ethanol amines were compared by their I.E. It was reported that the electronegative character of oxygen in ethanolamine results in a shift of electrons throughout the molecule in the direction of oxygen, making nitrogen center somewhat more positive and, as a result, more effectively adsorbed. Consequently, ethanolamine shows the same percentage of inhibition efficiency as compared to ethylamine. In the present set of compounds, also the electron withdrawing power of the oxygen reduces the $\mathrm{e}^{-}$donating power of the $\mathrm{N}$ by a large amount. However, the presence of the three lone pair of electrons in the adjacent atoms $\mathrm{N}-\mathrm{O}$ in isoxazole ring makes this moiety more polarizable and a powerful nucleophile. The protonated conjugate acid $>\mathrm{N}^{+} \mathrm{H}-\mathrm{O}$ - being weak may be involved in dynamic equilibrium with the neutral isoxazoles. While the neutral species get adsorbed on the anodic sites through interaction of lone pair of electron on N,O and aromatic $\pi$-electrons with $\mathrm{Fe}^{2+}$, the cationic species adsorb on the cathodic sites to decrease the evolution of hydrogen. Hence, more adsorption and inhibition. Similar explanation was given by Ali et al. [22] for the higher inhibition efficiency of bisisoxazolidines.

\section{SEM}

SEM photographs obtained for mild steel surface immersed in $1 \mathrm{M} \mathrm{H}_{2} \mathrm{SO}_{4}$ solutions for $3 \mathrm{hrs}$ in the absence and presence of $0.6 \mathrm{mM}$ of BIS1 are shown in Fig. 6 (a, b). It can be observed from Fig 6b, that the specimen surface was strongly damaged in the absence of the inhibitor. SEM image of inhibited mild 
steel specimen (Fig. 6a) reveals that a good protective adsorbed film is formed on the specimens surface, which suppresses the rate of corrosion, being responsible for the inhibition.

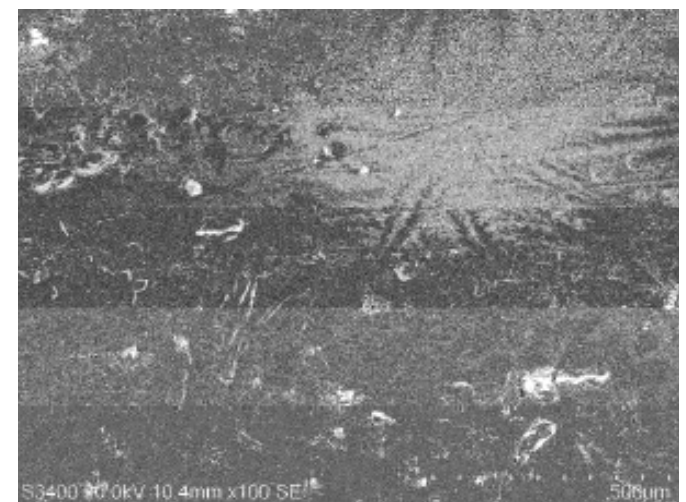

Figure 6a. SEM photograph of mild steel specimen after being corroded in $1 \mathrm{M} \mathrm{H}_{2} \mathrm{SO}_{4}$ solution for about $3 \mathrm{hrs}$ containing $0.6 \mathrm{mM}$ of BIS.

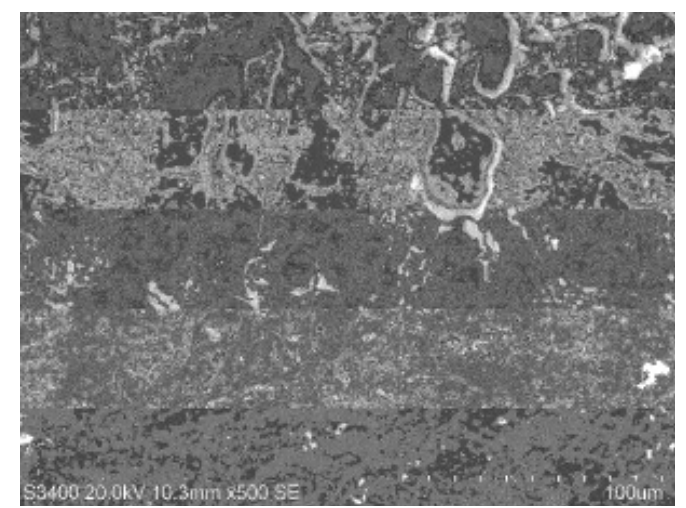

Figure 6b. SEM photograph of mild steel specimen after being corroded in $1 \mathrm{M} \mathrm{H}_{2} \mathrm{SO}_{4}$ solution for about 3 hrs.

\section{Conclusions}

- Benzoisoxazole and benzopyrazole derivatives exhibit excellent inhibition efficiency towards corrosion of mild steel in1 $\mathrm{M} \mathrm{H}_{2} \mathrm{SO}_{4}$.

- The optimum inhibition efficiency of these compounds was achieved at the concentration $0.6 \mathrm{mM}$.

- The inhibitors were adsorbed on the mild steel by physisorption mechanism.

- The adsorption of inhibitors on mild steel in $1 \mathrm{M} \mathrm{H}_{2} \mathrm{SO}_{4}$ obeys Langumuir adsorption isotherm.

- Potentiodynamic polarization studies suggest that the inhibitors are mixed type ones.

- The SEM proves the formation of a protective film of the inhibitors.

- The order of synergism observed due to the added halides is $\mathrm{KCl}<\mathrm{KBr}<\mathrm{KI}$. 


\section{References}

1. E.S. Ferreira, C. Giacomelli, F.C. Giacomelli, A. Spinelli, Mater. Chem. Phys. 83 (2004) 129-134. [10.1016/j.matchemphys.2003.09.020]

2. M.G. Fontana, Corrosion Engineering, third ed., McGraw-Hill, Singapore, 1986.

3. Y. Abboud, A. Abourriche, T. Saffaj, M. Berrada, M. Charrouf, A. Bennamara, H. Hannache, Desalination 237 (2009) 175-189. [10.1016/j.desal.2007.12.031]

4. J. Sinko, Prog. Org. Coat. 42 (2001) 267-282. [10.1016/S03009440(01)00202-8]

5. S.E. Manahan, Environmental Chemistry, sixth ed., Lewis, Boca Raton, 1994.

6. O. Krima, M. Bouachrineb, B. Hammouti, A. Elidrissia, M. Hamidib, Port. Electrochim. Acta 26 (2008) 283-289. [10.4152/pea.200803283]

7. M.A. Quraishi, S.K. Shukla, Mater. Chem. Phys. 113 (2009) 685-689. [10.1016/j.matchemphys.2008.08.028]

8. Y. Yan, W. Li, L. Cai, B. Hou, Electrochim. Acta 53 (2008) 5953-5960. [10.1016/j.electacta.2008.03.065]

9. F. Bentiss, M. Traisnel, L.Gengembre, M. Lagrenee, Appl. Surf. Sci. 161 (2000) 194-202. [10.1016/S0169-4332(00)00287-7]

10. J. Cruz, R. Martez, J. Genesca, E. Garcia-Ochoa, J. Electroanal. Chem. 566 (2004) 111-121. [10.1016/j.jelechem.2003.11.018]

11. M. Bouklah, A. Ouassini, B. Hammouti, A. El Idrissi, Appl. Surf. Sci. 250 (2005) 50-56. [10.1016/j.apsusc.2004.12.021]

12. A. Popova, M. Christov, S. Raicheva, E. Sokolova, Corros. Sci. 46 (2004) 1333-1350. [10.1016/j.corsci.2003.09.025]

13. S.A. Ali, M.T. Saeed, S.U. Rahman, Corros. Sci. 45 (2003) 253-266. [10.1016/S0010-938X(02)00099-9]

14. E. Rajanarendar, E.K. Rao, D. Karunakar, Ind. J. Chem. 43(B) (2006) 805807.

15. T. Szauer, A. Brandt, Electrochim. Acta 26 (1981) 1253-1256. [10.1016/0013-4686(81)85107-9]

16. Z.A. Foroulis, Proceedings of the seventh European symposium corrosion inhibitors, Ferrara,1990,149.

17. F.M. Donahue,K. Nobe, J. Electrochem. Soc. 112 (1965) 886-891. [10.1149/1.2423723]

18. E. Khamis, E.S.H. El-Ashry, A.K. Ibrahim, Br. Corros. J. 35 (2000) 150154.

19. Xueming Li, Libin Tang, Lin Li, Guannan Mu, Guangheng Liu, Corros. Sci. 48 (2006) 308-321. [10.1016/j.corsci.2004.11.029]

20. K.M. Ye, Mater. Protect. (Chinese) 23 (1990) 37-42.

21. Lloyyd E.Swearingen, Alfred F. Schram,(Pg. 180) (Ph.D. thesis, Graduate College of Lahom University)

22. S.A. Ali, H.A. Al-Muallem, S.U. Rahman, M.T. Saeed, Corros. Sci. 50 (2008) 3070-3077. [10.1016/j.corsci.2008.08.011] 